\title{
Lanthanides in basalts of Japan with three distinct types
}

\author{
Akimasa Masuda \\ Institute for Nuclear Study, University of Tokyo, \\ Tanashi-machi, Tokyo, Japan
}

(Received May 30, 1966)

\begin{abstract}
The lanthanides, La, Ce, Nd, Sm, Eu, Gd, Dy, Er and Yb were determined quantitatively for six basalts of Japan by the use of isotope dilution method. It is suggested that the high-alumina olivine basalt was a prim iry liquid-type material, the primary tholeiite was a primary solid-type material, and the alkali olivine basalt which was supposed to be primary was a secondary liquid-type material. This observation is in agreement with the consequence from the analysis of the relationship between thorium and uranium concentrations. The original depths for the aforementioned three magmas were estimated to be 200,150 and $220 \mathrm{~km}$, respectively, from the relative enrichment of lanthanides. A genetically close connection was corroborated for tholeiite and high-alumina basalt.
\end{abstract}

\section{INTRODUCTION}

MASUd A (1957) found a simple quantitative regularity between the abundance variation of lanthanides and the difference in the atomic number of lanthanides. This regularity developed into a more complete and far-reaching theory for lantha. nides (Masuda and Matsui, 1966). It should be also emphasized that such a theory is not limited to lanthanides, but the regularity found for lanthanides is merely an eminent representation of a more general rule for metallic elements (MASUDA, 1965 a, $1965 \mathrm{~b}$ ). Therefore the theory developed by us could be extended to such elements as thorium, uranium, lead, rubidium, and strontium (MASUdA, $1964 \mathrm{a}, 1965 \mathrm{c}, 1965 \mathrm{~d}$, 1966 a; Matsui, 1966).

According to our conclusion (MASuda and Matsur, 1966; Masuda, $1964 \mathrm{~b}$ ), the chondritic earth encountered a complete melting $4.55 \times 10^{9}$ years ago. If it is assumed that the formed crystals were fixed successively on the growing crystalline mantle, we can estimate the depth of the magma source (MASUDA, $1963 \mathrm{a}, 1964 \mathrm{c}$; Masuda and Matsur, 1965). In addition, there is a possibility that a similar study (MASUDA, $1966 \mathrm{~b}$ ) can present a chemical explanation on the genesis of the structure within the earth's mantle. It should be noted that the present study on basalts is closely connected with the theory and the model presented by us.

\section{Genetic Type of Material}

On the basis of the change of phase relation of rock-forming minerals under 
differing temperatures and pressures and/or the difference in major chemical composition, many discussions have been made on the origins of two or three different types of magmas (Kuno et al., 1957; Kuno, 1959, 1960; Kushiro and Kuno, 1963; Yoder and Tillex. 1962; Green and Ringwood, 1964; O'Hara, 1965). However, little discussions concerning the development of different types of basaltic magmas have been made from a sort of cosmogonical viewpoint.

At this point a definition of genetic type is made for silicate materials in relation to the development of terrestrial materials starting from the chondritic initial melt. Recognition of these genetic types will provide the earth science with a new aspect.

(a) Primary liquid-type material. This type of materials corresponds to the remnant liquids (melts) which can be produced through the fractional crystallization of chondritic initial melt, namely, through the successive removal of formed solids (crystals) from the liquids. In Fig. 1 where the concentration of uranium is plotted against that of thorium, the materials on the middle line belong to the primary liquid type. In a diagram, on the other hand, where the concentration ratio of lanthanides in a certain material relative to chondrite is plotted against the order of atomic number, the primary liquid type is characterized by a logarithmically linear (log-linear for short) curve. The lanthanides in the shales analysed by Minami (1935) and in the Hawaiian Kilauea basalt analysed by Schmitr et al. (1963) show such a character (Coryell et al., 1963; Matsui and Masuda, 1963). It is thought that this phenomenon is essentially due to the fact that the reciprocal of ionic radius of lanthanide changes linearly with the difference in atomic number (MAsuda, $1963 \mathrm{~b}$ ).

(b) Primary solid-type material. This type of material corresponds to the aggregate of solids (crystals) removed from the primary liquid-type melt. The materials which fall on the upper line in Fig. 1 belong to this type. Numerical values falling on the upper line in Fig. 1 is shifted onto the middle line by division by the partition coefficients of thorium and uranium. This couple of points correlated by virtue of partition coefficients represent a liquid and a solid just separated therefrom.

As to the lanthanide diagram as mentioned above, the material of primary solid type material shows a slightly convex curve. The curvature should be relatively great for the lighter members of lanthanides. For example, a mid-Atlantic basalt investigated by FREY and HASKIN (1964) shows a lanthanide pattern like this (Masuda, 1965 a). Theoretically, this slightly convex curve should be reduced to a log-linear curve characteristic of primary liquid-type material when dividing by the relevant partition coefficients.

(c) Secondary liquid-type material. If a melt of primary liquid type was quenched, the subsequent partial melting of such a rock, i.e., a frozen primary 


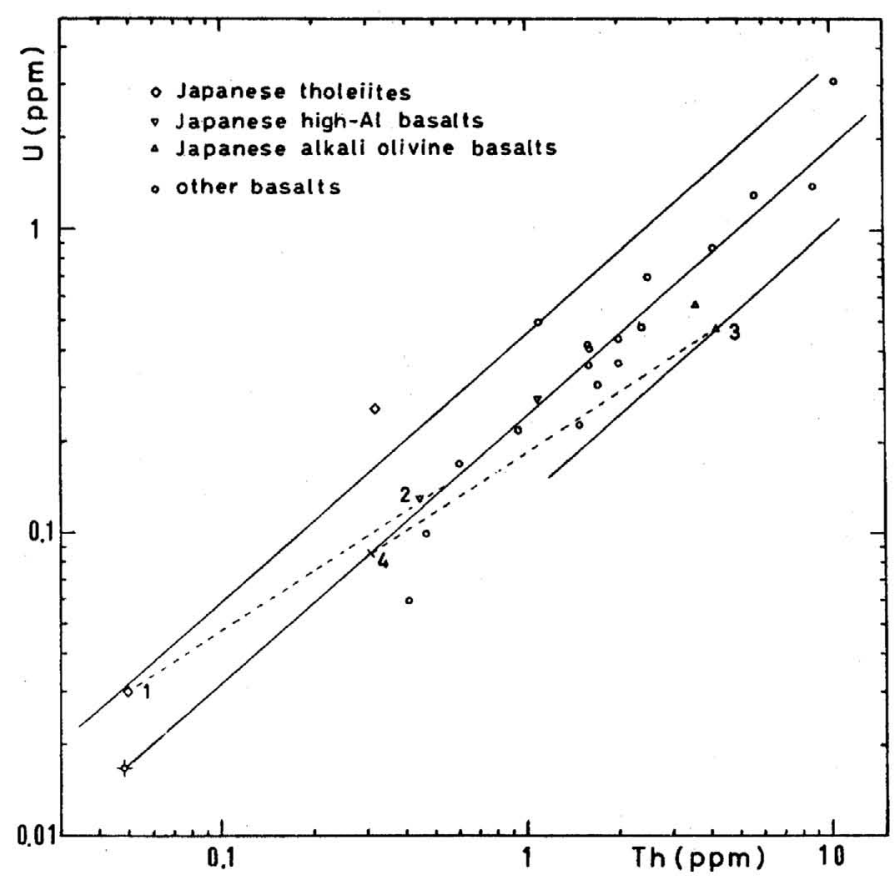

Fig. 1. Relationship between the concentrations of thorium and uranium in basalts investigated by HEIER and ROGERS (1963), with the indication of genetic relations (MASUDA, $1995 \mathrm{c}$ ).

liquid-type'material gives rise to a secondary liquid-type material. The point falling on the lower line in Fig. 1 represents the secondary liquid-type material. Numerical values falling on the lower line in Fig. 1 can be shifted onto the middle line by multiplication by the relevant partition coefficients of thorium and uranium.

Theoretical consideration predicts that, for the lanthanide diagram where the concentration ratio relative to chondrite is plotted logarithmically against the difference in atomic number, the secondary liquid type material should have a slightly concave curve with relatively great curvature at the lighter members of lanthanides. Furthermore it follows theoretically that a log-linear curve will be recovered when multiplying the observed values by the relevant partition coefficients. Such a lanthanide pattern will be presented below for the first time.

(d) Secondary solid type material. The complete melting of primary solid-type material and the subsequent crystallization can give rise to secondary solid-type material. According to the author's inspection, the lanthanides in Australian eclogite analysed by SснмiтT et al. (1964) appears to belong to this type.

MASUDA (1965 c) attempted an analysis of the distributional relationship between thorium and uranium determined by HeIER and Rogers (1963) and HeIER (1963). 
His analysis suggested strongly that the high-alumina basalt of Japan (point 2 in Fig. 1) was a primary liquid-type material, while the tholeiite of Japan (point 1 in Fig. 1) was a primary solid type material. It was also suggested that the alkali olivine basalt of Japan (point 3 in Fig. 1) could be regarded as a secondary liquidtype material. It is also an important finding that the points 1 and 3 can be brought to or near the point 2 when dividing or multiplying the relevant concentrations by the partition coefficients of thorium and uranium.

A similar situation was pointed out about the relationship between the isotopic ratio ${ }^{206} \mathrm{~Pb} /{ }^{207} \mathrm{~Pb}$ and the concentration of lead (see Fig. 2). That is, it was suggested (MASUDA, 1964 a) that the genetic relationship between pigeonitic rock series and hypersthenic rock series might be a conjugate liquid-solid relation as described above, for the partition coefficient for lead has been estimated to be nearly 0.3 (Pigeonitic rock series is inferred to have originated from tholeiite, while hypersthenic rock series from high alumina basalt with the contamination (KuNo, 1960).). When taking into account the possible error in the determination of lead, a similar liquid-solid relation is not far from conceivable between alkali rock series and hypersthenic rock series.

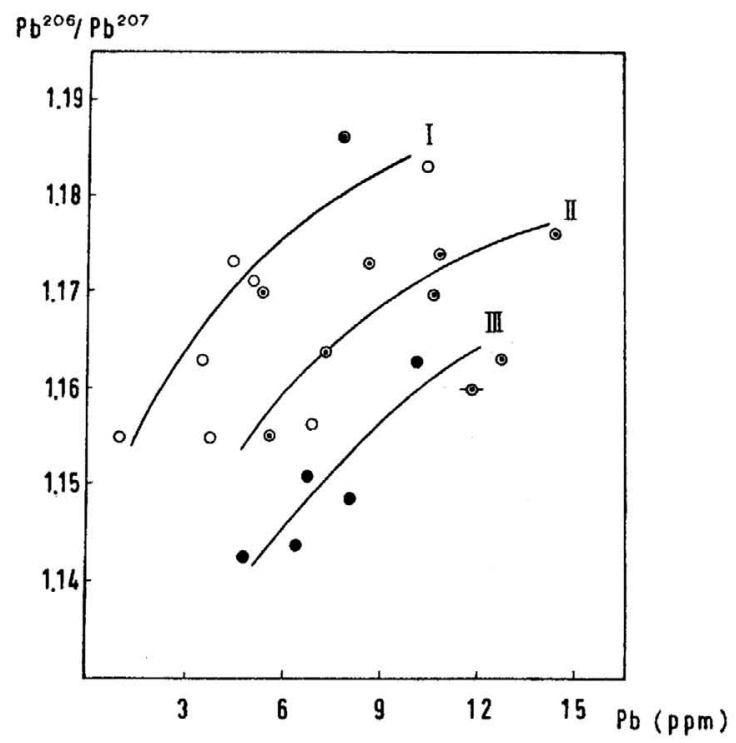

Fig. 2. Relationship between ${ }^{206} \mathrm{~Pb} /{ }^{207} \mathrm{~Pb}$ ratio and lead concentration in basalts of Japan; open circles refer to pigeonitic rock series, double circles to hypersthenic rock series, and solid circles to alkali rock series (MASUDA, 1964 d).

If the high-alumina basalt is a primary liquid type material, it should have the $\log$ linear, chondrite-normalized pattern for lanthanides therein. If the tholeiite and the alkali olivine basalt of Japan are, respectively, the primary solid-type and 
the secondary liquid-type material, these basalt should have a slightly convex and a slightly concave pattern, respectively, for lanthanides therein. Moreover, it is anticipated that the slopes of the log-linear lines recovered from tholeiite and alkali olivine basalt are similar with the slope of the high-alumina basalt. These anticipations are the motive to undertake the present study.

\section{EXPERIMENTAL}

In the recent determination of rare-earth elements (Schmiтr et al., 1963; HASKIN and Gehl, 1962; Towell, 1963; Towell et al.. 1965), use was made of the neutron activation method. In the present study the isotope dilution method was employed. While the isotope dilution method is disadvantageous in that mono-isotopic elements cannot be determined, it has an advantage in that the determination can be made with higher accuracies and with less time consumption. Like the determination based on the activation analysis, the separation by ion exchange resin was employed in the present study. The procedure is as follows.

Evaporate the ca. $3 \mathrm{~N}$ nitric acid solution containing the adequate amounts of enriched isotopes to dryness in a platinum dish. The enriched isotopes used for spikes are ${ }^{138} \mathrm{La},{ }^{142} \mathrm{Ce},{ }^{143} \mathrm{Nd},{ }^{147} \mathrm{Sm},{ }^{151} \mathrm{Eu},{ }^{157} \mathrm{Gd},{ }^{164} \mathrm{Dy},{ }^{170} \mathrm{Er}$ and ${ }^{171} \mathrm{Yb}$. Place about $100-500 \mathrm{mg}$ of powdered sample in the platinum dish. Decompose the sample with $15 \mathrm{ml}$ of concentrated $\mathrm{HF}$ and $3 \mathrm{ml}$ of $\mathrm{HClO}_{4}$ with occasional stirring with a platinum wire on a hot plate. When most (not all) of perchloric acid has been driven off, dissolve the salts in $5-10 \mathrm{ml}$ of $0.5 \mathrm{~N} \mathrm{HCl}$. Load the solution onto the $15 \mathrm{ml}$ column of 100-200 mesh Dowex $50 \mathrm{~W} \cdot \mathrm{X} 8$ cation exchange resin. Elute most of cations with $130 \mathrm{ml}$ of $2 \mathrm{~N} \mathrm{HCl}$ at a rate of $20-30$ drops per minute $(1.5-2.5 \mathrm{ml}$ per minute). Discard the eluate. Then elute the lanthanides with $100 \mathrm{ml}$ of $6 \mathrm{~N} \mathrm{HCl}$. Collect the eluate in a $100 \mathrm{ml}$ polyethylene bottle. Place about one-fourth of the $6 \mathrm{~N} \mathrm{HCl}$ eluate in a platinum dish and evaporate to dryness. Dissolve the residue in about $1 \mathrm{ml}$ of $0.5 \mathrm{~N} \mathrm{HCl}$. Load the solution onto a $0.5 \mathrm{ml}$ column $(4 \mathrm{~mm}$ in diameter and $40 \mathrm{~mm}$ long) of 200-400 mesh Dowex $50 \mathrm{~W} \cdot \mathrm{X} 8$ cation exchange resin. Elute most of remnant cations with $5 \mathrm{ml}$ of $2 \mathrm{~N} \mathrm{HCl}$ at a rate of 1 droplet per about 30 seconds (The elution takes 50 minutes.). Elute the lanthanides with $4 \mathrm{ml}$ of $6 \mathrm{~N} \mathrm{HCl}$, collecting the eluate in a platinum dish. Evaporate the solution to dryness. Add several drops of concentrated nitric acid and evaporate to dryness again. Add several drops of water and dry the solution on a tungsten filament to be used for mass spectrometry. For the all procedure described above the redistilled water was used.

Since the triple filament ion source is necessary for the determination of europium, this element was determined for only one rock, to save the allowed time. A tungsten single filament ion source produced monoxide ion for lanthanides with the exception of europium and ytterbium. The ion beam was measured with the aid of a secondary electron multiplier. 


\section{SAMPLE}

The lanthanide determination was made for the following six rock samples comprising one tholeiite, one high-alumina basalt, and four alkali olivine basalts.

(i) High-alumina olivine basalt. A lava of Fuji Volcano, collected at a quarry at Shimotokari (=Simotokari), Mishima City, Shizuoka Prefecture.

(ii) Tholeiitic augite-olivine basalt. A lava of Pliocene Hata basalt group, near the ridge NE of Hata, Tanna Basin, Izu Peninsula, Shizuoka Prefecture. The chemical analysis of the rock indicates that it is close to the parental tholeiite magma (Kuno, personal communication).

(iii) Alkali olivine basalt. A younger Pliocene lava, $500 \mathrm{~m} \mathrm{NNW}$ of Misaki, south to Saigo Bay, Oki Dogo Island. Of the alkali rocks of Japan, this rock is thought to be the closest to the parental alkali basalt magma (Uсніміzu, 1966).

(iv) Alkali olivine basalt. A Pleistocene lava, east coast of the island of Takashima, NW of Karatsu, northern Kyushu (=Kyusyu).

(v) Alkali olivine basalt. A small plateau just west of Takakura, W of Agematsu, Kiso district, Nagano Prefecture.

(vi) Olivine dolerite. A younger Miocene sheet, $5 \mathrm{~km} \mathrm{SSW}$ of Atsumi, southwest coast of Yamagata Prefecture.

\section{RESULTS}

The results of determination is presented in Table 1 together with the abundance in chondrite (Schmitr et al., 1963). Owing to the inadequate addition of ${ }^{138} \mathrm{La}$ as spike, the determination of lanthanum was not made for some rocks. The uncertainty for lanthanum indicates the possible error in reading the recorded peak height of ${ }^{138} \mathrm{La}$ (Even the enriched ${ }^{138} \mathrm{La}$ contained as low as $2.17 \% \mathrm{La}^{138}$.).

At first a specific discussion will be given to each sample and then a further discussion will be given to the whole result under theoretical consideration.

(i) High alumina basalt, Mishima. As shown in Fig. 3, the chondrite-normalized lanthanide pattern (the lanthanide pattern for short) is $\log$-linear with $\log s=0.0391$ (The value of slope coefficient $s$ indicates the relative enrichment between the adjacent lanthanides (MAsuda and Matsur, 1966).). It is seen, on the other hand, the point representing cerium (a cross in Fig. 3) is too distant from the smooth log-linear line. It was confirmed that this deviation is not due to any errors including the error in standardization. At the same time the cerium deviation was found to be considerably common to other samples, too. This suggests strongly that the average abundance of cerium in chondrite (Schmrt et al., 1963) is relatively too high to be employed for the normalization of basalts of Japan (Alternatively the chondritic abundances of lanthanides other than cerium may be too 
Table 1. Lanthanides concentrations in basalts of Japan together with abundances in chondrites (in $\mathrm{ppm}$ )

\begin{tabular}{|c|c|c|c|c|c|c|c|}
\hline & $(i)^{* 1}$ & $(\mathrm{ii})^{* 2}$ & $(\mathrm{iii})^{* 3}$ & $(\mathrm{iv})^{* 4}$ & $(v)^{* 5}$ & $(v i)^{* 6}$ & $(\mathrm{vii})^{* 7}$ \\
\hline La & $8.8-12.2$ & - & $40-48$ & $33-42$ & - & $21.7-26.2$ & 0.32 \\
\hline $\mathrm{Ce}$ & 21.5 & 4.74 & 59.3 & 63.1 & 45.8 & 35.7 & 0.90 \\
\hline $\mathrm{Nd}$ & 15.3 & 4.52 & 30.5 & 29.5 & 24.1 & 16.0 & 0.57 \\
\hline $\mathrm{Sm}$ & 4.36 & 1.94 & 6.31 & 6.06 & 6.20 & 4.50 & 0.21 \\
\hline $\mathrm{Eu}$ & 1.31 & - & - & - & - & - & 0.074 \\
\hline Gd & 5.46 & 2.55 & 6.70 & 6.43 & 5.70 & 4.37 & 0.31 \\
\hline Dy & 4.63 & 2.53 & 5.16 & 4.14 & 4.69 & 3,99 & 0.30 \\
\hline $\mathrm{Er}$ & 2.53 & 1.66 & 2.34 & 1.92 & 2.34 & 2.36 & 0.21 \\
\hline $\mathrm{Yb}$ & 1.97 & 1.39 & 1.59 & 1.16 & 1.56 & 2.05 & 0.18 \\
\hline
\end{tabular}

*1 High-alumina basalt, Mishima.

*2 Tholeiitic basalt, Tanna.

*3 Alkali olivine basalt, Oki.

*4 Alkali olivine basalt, Takashima.

*5 Alkali olivine basalt, Kiso.

*6 Olivine dolerite, Atsumi.

*7 Average in 12 chondrites (ScHMIT' et al., 1963).

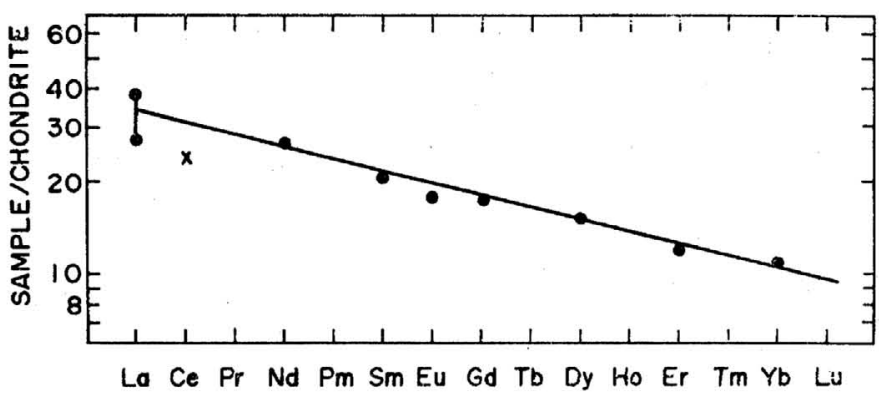

Fig. 3. Chondrite-normalized lanthanide pattern of high-alumina basalt, Mishima:

low.). For this reason the chondritic abundance of cerium for the normalization was taken to be $0.70 \mathrm{ppm}$, which value makes point for cerium fall on the smooth curve in Fig. 3. This modified abundance of cerium will be also employed for normalization of other samples.

(ii) Tholeiitic basalt. Tanna. The solid circles in Fig. 4 refer to the observed values, showing a slightly convex pattern characteristic of a primary solid-type material. If this rock is a typical primary solid-type material, it is expected that a log-linear line should be recovered when dividing the observed values by the pertinent partition coefficients. The apparent partition coefficients estimated by us (MAsuda and Matsui, 1966) are presented in Table 2. Indeed, when the observed 
Table 2. Partition coefficients of lanthanides for non-inflexional pattern (MASUDA and MATSUI, 1966)

\begin{tabular}{llllllllll}
\hline $\mathrm{La}$ & 0.119 & $\mathrm{Nd}$ & 0.23 & $\mathrm{Eu}$ & 0.33 & $\mathrm{Dy}$ & 0.44 & $\mathrm{Tm}$ & 0.55 \\
$\mathrm{Ce}$ & 0.154 & $\mathrm{Pm}$ & 0.26 & $\mathrm{Gd}$ & 0.37 & $\mathrm{Ho}$ & 0.47 & $\mathrm{Yb}$ & 0.58 \\
$\mathrm{Pr}$ & 0.190 & $\mathrm{Sm}$ & 0.30 & $\mathrm{~Tb}$ & 0.40 & $\mathrm{Er}$ & 0.51 & $\mathrm{Lu}$ & 0.62 \\
\hline
\end{tabular}

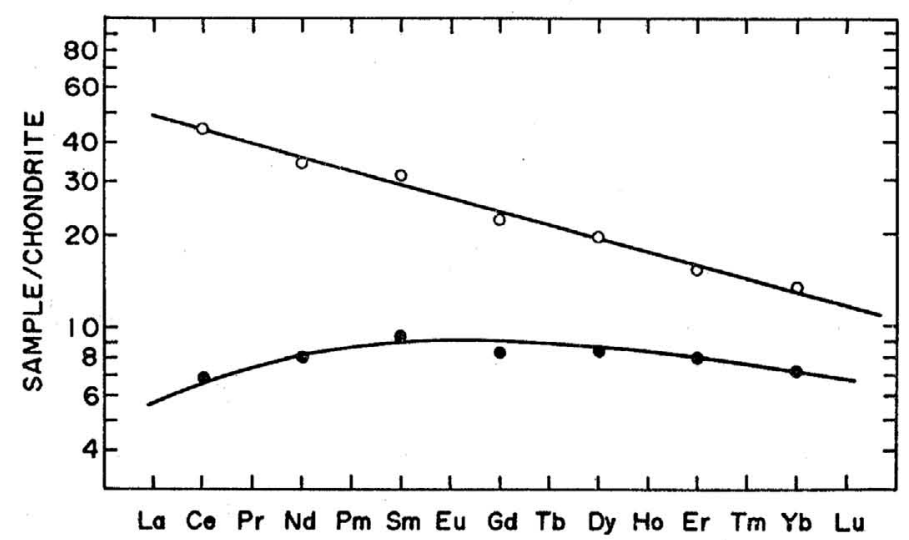

Fig. 4. Chondrite-normalized lanthanide pattern of tholeiitic basalt, Tanna; solid circles refer to the observed values and open circles to those obtained when dividing by the partition coefficients.

values are divided by the partition coefficients presented in Table 2, a log-linear line characteristic of a primary liquid-type material is recovered (see the open circles in Fig. 4). This recovered log-linear line has an inclination corresponding to $\log s=0.0429$. It is noteworthy that the recovered liner representing the conjugate liquid resembles the line for high-alumina basalt, a fact which is in agreement with the theoretical anticipation. A further consideration will be made later on.

(iii) Alkali olivine basalt, Oki. As mentioned above, this rock is inferred to be close to or represent the parental alkali olivine basalt magma. The observed values are represented by the solid circles in Fig. 5. Obviously the lanthanide pattern of this rock is slightly concave, indicating the character of a secondary liquid-type material. As shown by the open circles in Fig. 5, when the observed values are multiplied by the relevant partition coefficients, a log-linear pattern is recovered in agreement with the theoretical anticipation. The log-linear line recovered here can be interpreted as representing the lanthanide in the rock the partial melting of which gave birth to the alkali olivine basalt under consideration. The logarithm of the slope coefficient $s$ of the recovered line is 0.0375 .

(iv) Alkali olivine basalt, Takashima. The solid circles in Fig. 6 shows that this lava is also a secondary liquid-type material. The logarithm of the slope coefficient of the recovered log-linear line is 0.0466 . This value is greater than that for the 


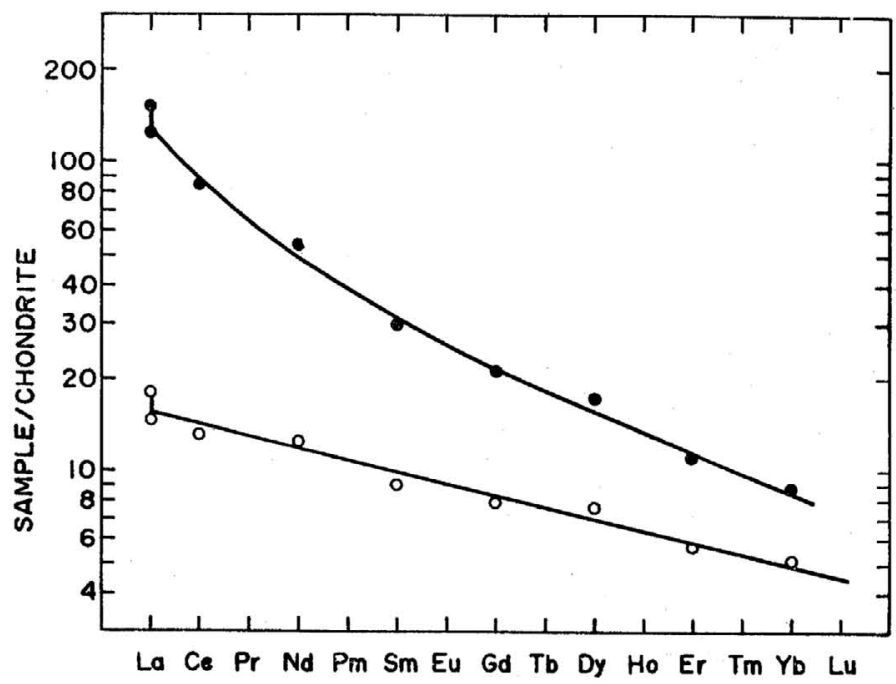

Fig. 5. Chondrite-normalized lanthanide pattern of alkali olivine basalt, Oki; solid circles refer to the observed values and open circles to those obtained when multiplying by the partition coefficients.

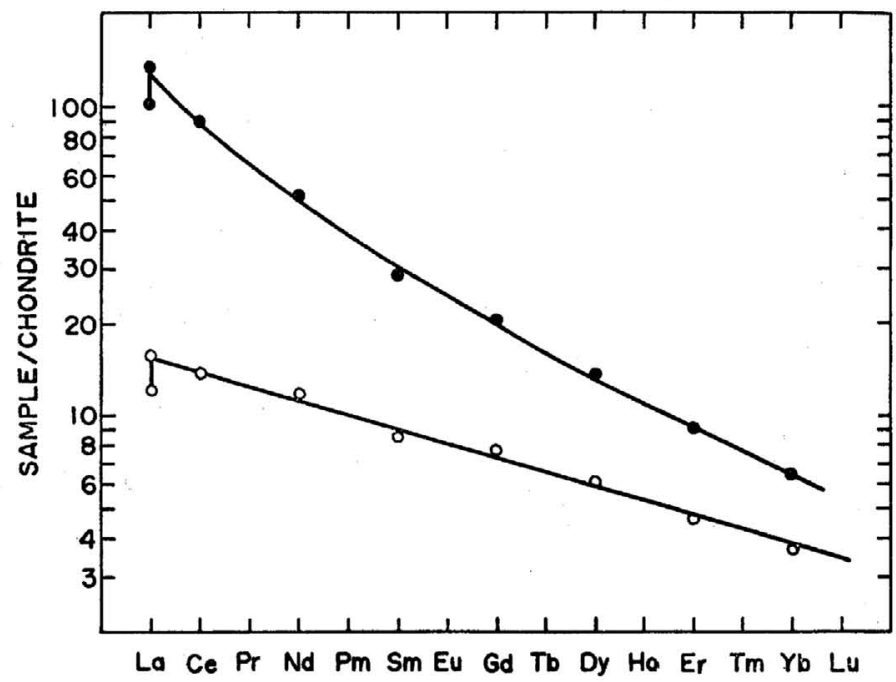

Fig. 6. Chondrite-normalized lanthanide pattern of alkali olivine basalt, Takashima; solid circles refer to the observed values and open circles to those obtained when multiplying by the partition coefficients.

alkali olivine basalt, Oki. This suggests that the alkali olivine basalt, Takashima, is a product of later stage than the alkali olivine basalt, Oki. A seemingly very slightly convex curve of the recovered line may suggest that this rock is not an 
ideally chilled melt, but concentrates more or less the separated crystals.

(v) Alkali olivine basalt, Kiso. As shown by solid circles in Fig. 7, this rock has a characteristic of secondary liquid-type material. However, the pattern isee open circles) obtained by multiplication by the partition coefficients is not perfectly log-linear, but slightly convex. This indicates that the rock under consideration is not purely a chilled secondary liquid-type melt, but a mixture of primary liquid-type material and secondary liquid-type material (In this case primary liquidtype material represents the solid (crystal) phase relative to secondary liquid-type melt.). If this rock is assumed to be one-to-one mixture of primary liquid-type solid and secondary liquid-type melt, a log-linear line pertaining to the primary liquid-type material is recovered as shown in Fig. 8 . The log-linear line recovered here has $\log s=0.0400$.

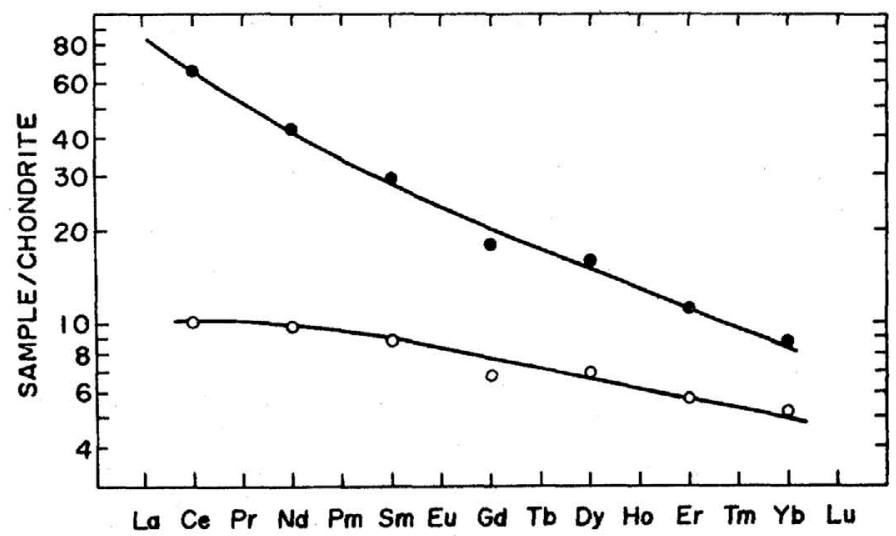

Fig. 7. Chondrite-normalized lanthanide pattern of alkali olivine basalt, Kiso; solid circles refer to the observed values and open circles to those obtained when multiplying by the partition coefficients.

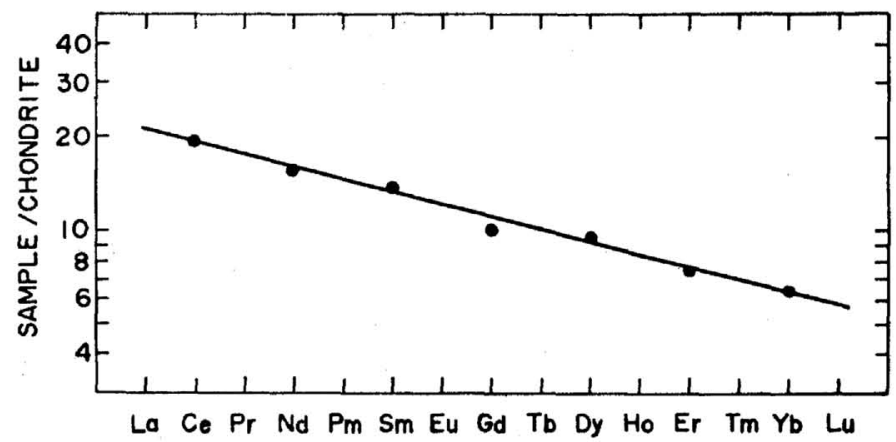

Fig. 8. Primary liquid-type lanthanide pattern recovered from Kiso basalt by assuming a one-to-one mixture of primary liquid-type material and secondary liquid-type material for Kiso basalt. 


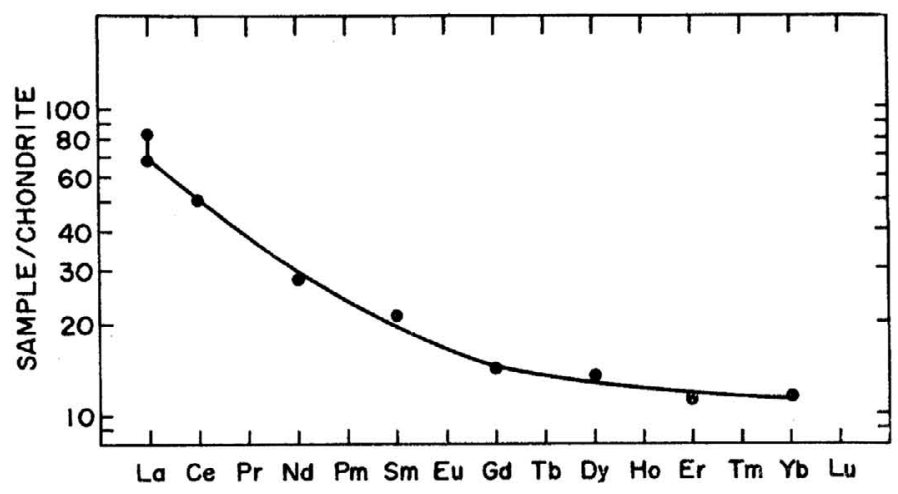

Fig. 9. Chondrite-normalized lanthanide pattern of olivine dolerite, Atsumi.

(vi) Olivine dolerite, Atsumi. The lanthanide pattern (see Fig. 9) of this rock appears to be a secondary liquid-type material with an inflexion probably due to calcium effect (MASUDA, $1965 \mathrm{e}$ ). Since the partition coefficients for the process involving the inflexion effect are not yet established, it is difficult to make a treatment like above. Conversely, however, it may be possible to estimate the pertinent partition coefficients. To do this, it is necessary to know the lanthanide pattern of the source material the partial melting of which gave rise to the magma under

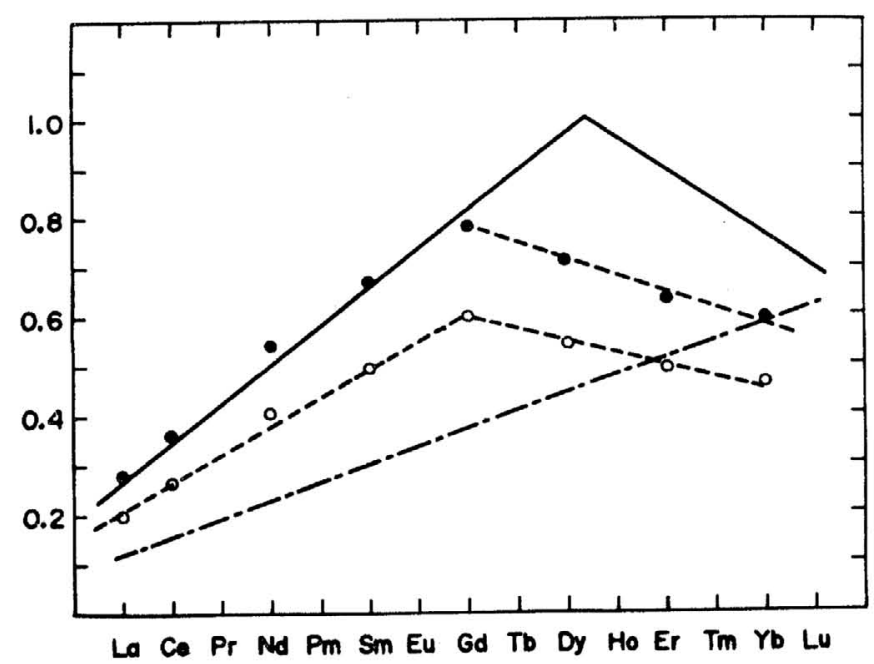

Fig. 10. Tentatively estimated partition coefficients for the partial melting involving an inflexion effect; solid circles refer to the values obtained as the ratios of the recovered log-linear line of Kiso basalt to Atsumi dolerite and open circles to the ratios of the recovered loglinear line of Oki basalt to Atsumi dolerite (cf. text). 
consideration. Here let us assume that the lanthanide pattern of the source material was similar to that recovered from Kiso alkali olivine basalt or Oki alkali olivine basalt. Then the partition coefficients responsible for the formation of the magma in question are estimated as shown in Fig. 10. The solid line in Fig. 10 indicates the partition coefficients independently obtained on the basis of a theoretical hypothesis (MASUDA, $1965 \mathrm{e}$ ). The partition coefficients tentatively estimated from a comparison of the pattern of Atsumi dolerite with that recovered from Kiso basalt are in remarkable agreement, from La through $\mathrm{Gd}$, with the hypothetically estimated ones (A chain line drawn in Fig. 10 indicates the partition coefficients for the process with no inflexion effect, which are presented also in Table 2.). The shift of inflexion point presents a problem to be solved.

\section{Discussion}

We derived the following equation which connects the slope coefficient $s$ with the liquid fraction value $f_{W}$ (Masuda and Matsui, 1966).

$$
\log f_{W}=-\frac{\log s}{D}
$$

where $D$ is a difference in the value of partition coefficient between the adjacent lanthanides. According to our studies (Masuda and Matsui, 1966; Masuda, 1964 e), $D$ can be evaluated to be 0.0352 . It is of much interest to evaluate the liquid fraction values from the siope coefficients for the three different types of probably parental basalts. The logarithms of slope coefficients obtained above are tabulated in Table 3 together with other quantities estimated from $s$. When the liquid fraction value is evaluated, we can also estimate the depth or thickness of magma source (Masuda, $1964 \mathrm{c}$; Masuda and Matsui, 1965) as well as the concentration of lanthanide in the primeval melt.

Table 3. Logarithmic slope coefficients for primary liquid-type lanthanide pattern (directly and indirectly obtained), liquid fraction values, and depths estimated therefrom.

\begin{tabular}{lcccc}
\hline \multicolumn{1}{c}{ specimen } & $\log s$ & $\log f_{W}$ & $f_{W}$ & $\begin{array}{c}\text { depth, } \\
\mathrm{km}\end{array}$ \\
\hline High-alumina basalt & 0.0391 & -1.111 & $1 / 12.9$ & 197 \\
Tholeiitic basalt & 0.0429 & -1.219 & $1 / 16.5$ & 153 \\
A. O. basalt*, Oki & 0.0375 & -1.065 & $1 / 11.6$ & 218 \\
A. O. basalt, Takashima & 0.0466 & -1.324 & $1 / 21.1$ & 120 \\
A. O. basalt, Kiso & 0.0400 & -1.135 & $1 / 13.7$ & 186 \\
\hline
\end{tabular}

* A. O. basalt stands for alkali olivine basalt.

First of all, it is an important fact that the slope coefficients of directly observed and theoretically recovered $\log$-linear lines are similar to each other for 
three "parental" basalt magmas. It is also interesting that the liquid fraction value pertaining to supposedly parental magma is in the order of tholeiite $(1 / 16.5)$ $<$ high-alumina basalt $(1 / 12.9)<$ alkali olivine basalt $(1 / 11.6)$. These liquid fraction values estimated from the slope coefficients can be reduced in turn to the depths of about 150, 200 and $220 \mathrm{~km}$, respectively. Isotopic composition of lead in the basalts of Japan suggests the liquid fraction value of about 1/17 (MAsuda, 1964 c, $1964 \mathrm{~d})$. According to the analysis of the distributional relationship of thorium and uranium determined by Heier and Rogers (1963), the $f_{W}$ for tholeiite and highalumina was estimated to be $1 / 17$, while that for alkali olivine basalt to be $1 / 7.4$ (Masuda, 1965 c). The resuit from uranium and thorium concentrations may be more subject to error. Besides, it is a problem whether or not the analysed rock specimens are the same, and that, even if they are from the same locality, the analysed parts are not the same. In spite of these uncertainties, it is evident that the results from the different elements are more or less in accord with each other. Moreover, it must be added that, based on seismic data, Kuno (1960) estimated the original depths of tholeiite, high-alumina basalt, and alkali olivine basalt to be shallower than $200 \mathrm{~km}$, about $200 \mathrm{~km}$, and greater than $200 \mathrm{~km}$, respectively.

For the primary liquid type material the differential enrichment $R$ of an element with a partition coefficient $k$ can be calculated from the theoretical equation

$$
\log R=-(1-k) \log f_{W} .
$$

Since the value of $\log f_{w}$ can be obtained from $\log s$ (cf: Equation 1), it is possible to evaluate the differential enrichment factor $R$ from $\log s$. In Table 4 is shown the calculated enrichment factor $R$ for lanthanum together with the corresponding value extrapolated from the observed or recovered log-linear line. In this connection it is necessary to note that the concentration of lithophile element in the initial oxide melt of the earth is inferred to be 1.20 times the concentration in the whole chondrite, because the earth's initial chondritic material is inferred to have contained 17\% non-oxide components (MASUDA, 1965 a). Accordingly the "observed" values presented in Tab. 4 is smaller by a factor of 1.2 than the directly extra-

Table 4. Comparison of calculated differential enrichment $(R)$ for La with the "observed" one $(B)^{*}$.

\begin{tabular}{lccl}
\hline \multicolumn{1}{c}{ specimen } & $R$ & $B$ & $B / R$ \\
\hline High-alumina basalt & 9.35 & 28.3 & 3.05 \\
Tholeiitic basalt & 11.9 & 39.2 & 3.29 \\
A. O. basalt, Oki & 8.68 & 12.7 & 1.46 \\
A. O. basalt, Takashima & 14.65 & 12.9 & 0.88 \\
A. O. basalt, Kiso & 10.00 & 17.6 & 1.76 \\
\hline
\end{tabular}

* Observed enrichment $(B)$ here refers to the value obtained by dividing the value extrapolated from a smooth curve by a façtor 1.2 (cf. text). 
polated ones. It is found that the ratio of observed to calculated enrichment is close to unity for alkali rocks. If the initial concentration of lanthanum is taken to be $0.47 \mathrm{ppm}$, the observed-to-calculated enrichment ratio becomes unity for the alkali olivine basalt, Oki. If the initial concentration of lanthanum is taken to be $0.28 \mathrm{ppm}$, the observed-to-calculated ratio becomes just unity for the alkali olivine basalt, Takashima. According to the determinations by Schmiтr et al. (1963), the concentration of lanthanum in chondrites ranges from $0.15 \mathrm{ppm}$ to $0.46 \mathrm{ppm}$. Therefore it is admissible to infer that the alkali olivine basalt developed from the initial chondritic material without appreciable non-differential enrichment of entire lanthanides. For the high-alumina basalt and tholeiite, on the other hand, the observed-to-calculated enrichment ratios of lanthanum are 3.05 and 3.29 , respectively, suggesting the non-differential enrichment of entire lanthanides by a factor of about 3. This fact can be accounted for either by assuming the non-differential enrichment of entire lanthanides at the stage of the generation of magma or by assuming that the initial primeval material responsible for these rocks were enriched in all lanthanides by a factor of nearly three as compared with the average chondrite. A fact that the concentrations of all lanthanides in eucrites (a group of calciumrich achondrites) are ten times as high as in the average chondrite (ScHMIrT et al., 1963) may give a suggestion to the latter interpretation. A fact that the observedto-calculated enrichment ratio for tholeiite is substantially identical with that for high alumina basalt suggests strongly the genetically close connection of these materials.

The observed-to-calculated enrichment ratio for alkali olivine basalt, Kiso is somewhat higher than those for other two alkali olivine basalts which have typical secondary liquid type characters. This somewhat high enrichment ratio may be related with the intermediate character as disclosed above. Besides, it may be related with the fact that this rock occurs at a border area between the typical alkali rock province and the province characterized by high-alumina basalt or tholeiite.

It is also a remarkable fact that, while the lanthanide pattern with an in. flection is very frequently found for continental rocks, the basic pattern for basalts of Japanese Islands appears to be that with no inflexion.

\section{ACKNowledgements}

The author wishes to thank Prof. H. KUNO for providing the rock specimens, and to Prof. M. HONDA for comments on chemical separation. Sincere thanks are extended to Dr. I. KUSHIRO for offer of the rock specimens and for helpful discussions. The author is indebted to $\mathrm{Mr}$. $\mathrm{K}$. IWATA for help in the maintenance of the mass spectrometer.

\section{REFERENCES}

Coryeli, C. D., Chase, J. W, and Winchester, J. W. (1963) A procedure for geochemical interpretation of terrestrial rare-earth abundance patterns. J. Geophys. Res., 68, 559-566. 
FREY, A. F. and HASKIN, L. (1964) Rare earths in oceanic basalts. ibid., 69, 775-780.

GREEN, D. H. and RiNGwOOD, A. E. (1964) Fractionation of basalt magmas at high pressures. Nature, 201, 1276-1279.

HASKIN, L. A. and GEHL, M. A. (1962) The rare-earth distribution in sediments. J. Geophys. Res., 67, 2537-2541.

HEIER. K. S. (1963) Uranium, thorium and potassium in eclogitic rocks. Geochim. Cosmochim. Acta, 27, 849-860.

HEIER. K. S. and RogerS, J. J. W. (1963) Radiometric determination of thorium, uranium, and potassium in basalts and in two magmatic differentiation series. ibid., 27, 137-154.

KUNO, H. (1959) Origin of Cenozoic petrographic provinces of Japan and surrounding areas. Bull. Volcanol. 2nd Ser. 20, 37-76.

Kuno, H. (1960) High-alumina basalt. J. Petrol., 1, 121-145.

KUNO, H., YAMASAKI, K., IIDA, C., and NAGASHIMA, K. (1957) Differentiation of Hawaiian magmas. Japan. J. Geol. Geography, 28, 179-218.

KUSHIRO, I. and KUNO, H. (1963) Origin of primary basalt magmas and classification of basaltic rocks. J. Petrol., 4, 75-89.

MASUDA, A. (1957) Simple regularity in the variation of relative abundances of rare earth elements. J. Earth Sci., Nagoya Univ., 5, 125-134.

MASUDA, A. (1963 a) The depth of magma source tentatively estimated from the lanthanide pattern. Inst. Nucl. Study, Univ. Tokyo, INS Report 51. 14 pp.

MASUDA, A. (1963 b) Partition coefficients and reciprocal ionic radii. ibid., INSJ-54. 17 pp.

MASUDA, A. (1964 a) Content of lead in the earth's initial chondrite-like oxide mass and the partition coefficient of lead for crystallization of silicate melt. Nature, 203, 1161-1162.

MASUDA, A. (1964 b) Relative distribution of thorium, uranium, and lead estimated from the isotopic composition of lead in ores. ibid., 203, 1062.

MASUDA, A. (1964 c) Depth of source of lead. ibid., 204, 567-569.

MASUDA, A. (1964 d) Lead isotope composition in volcanic rocks of Japan. Geochim. Cosmochim. Acta, 28, 291-303.

MASUDA, A. (1964 e) The possible genesis of mantle and crust, viewed from the abundances of lanthanides in meteorites and terrestrial materials. Chigaku Zasshi, 73, 139-145.

MASUDA, A. (1965 a) The abundance ratios between the average basic rock and chondrites as a function of reciprocal ionic radii. Tectonophys., 2, 299-317.

MASUDA, A. (1965 b). Size effect of oxygen anion on partition coefficients. Nature, 205, 971972.

MASUDA, A. (1965 c) Geothermal and petrogenetic implications of the analysis of the distributional relationship between thorium and uranium. Tectonophys., 2, 69-81.

MASUDA, A. (1965 d) Geochemical constants for rubidium and strontium in basic rocks. Nature, 205, $555-558$.

MASUDA, A. (1965 e) Variation of partition coefficients. ibid., 205, 1098-1099.

MASUDA, A. (1966 a) A geochemical coincidence between strontium isotopes and lead isotopes. Chem. Geol., 1, 57-60.

MASUDA, A. (1966 b) Genesis of the earth's crust and the structure within the mantle: A unified chemical theory. ibid., 1, 155-163.

MASUDA, A. and MATSUI, Y. (1965) Depths of magma source of an eclogite and a peridotite. Japan. J. Geol. Geography, 36, 163-169.

MASUDA, A. and MATSUI, Y. (1966) The difference in lanthanide abundance pattern between the crust and the chondrite and its possible meaning to the genesis of crust and mantle. Geochim. Cosmochim. Acta, 30, 239-250.

MATSUI, Y. (1966) Parallelism between the rare-earth fractionation and the Rb to Sr ratio in the earth's mantle. Japan. J. Geol. Geography, (in press).

MATSUI, Y. and MASUDA, A. (1963) On the variation in relative abundances of rare earth 
elements among meteorites, igneous rocks, and sediments. Geochim. Cosmochim. Acta, 27, 547-549.

MINAMI, E. (1935) Gehalte an seltenen Erden in europäischen und japanischen Tonschiefern. Nachr. Ges. Wiss. Göttingen, IV. Math.-Phys. Kl., N.F., 1, 155-170.

O'HARA, M. J. (1965) Primary magmas and the origin of basalts. Scot. J. Geol. 1, 19-40.

SchmitT, R. A., SMITh, R. H., LASCH, J. E., Mosen, A. W., Olehy, D. A., and VAsilevskis, J. (1963) Abundances of the fourteen rare earth elements, scandium and yttrium in meteoritic and terrestrial matter. Geochim. Cosmochim. Acta, 27, 577-622.

SchmitT, R. A., SMITH, R. H., and Olehy, D. A. (1964) Rare-earth, yttrium and scandium abundances in meteoritic and terrestrial matter II. ibid., 28, 67.86.

TOWELL, D. G. (1963) Ph. D. thesis, Massachusetts Institute of Technology.

TOWELL, D. G., WINChester, J. W., and SPIRN, R. V. (1965) Rare-earth distributions in some rocks and associated minerals of the batholith of southern California. J. Geophys. Res., 70, 3485-3496.

UснiмizU, M. (1966) Geology and petrology of alkali rocks from Dogo, Oki Islands. J. Fac. Sci., Univ. Tokyo, Sect. 2, 16, 85-159.

YODER, H. S., Jr., and TILLEY, C. E. (1962) Origin of basalt magmas: An experimental study of natural and synthetic rock systems. J. Petrol., 3, 342-532. 